\title{
Prevalence and immediate outcome of candida colonized preterm neonates admitted to Special Care Unit of Mulago Hospital, Kampala Uganda
}

\author{
Yaser Abdallah ${ }^{1}$, Deogratias Kaddu-Mulindwa²+, Jolly Nankunda ${ }^{1}$, Philippa M Musoke
}

1. Department of Paediatrics and Child Health, Makerere University College of Health Sciences

2. Department of Microbiology, Makerere University College of Health Sciences

+ Deceased

\begin{abstract}
Background: Candida species is the third commonest cause of sepsis among neonates. Colonization by Candida is a predictor for candidemia among preterm neonates.

Objectives: To determine prevalence of early Candida colonization and early outcome among colonized preterm neonates admitted to Mulago hospital Special Care Unit.

Methods: A prospective observational cohort was conducted between December 2008 and April 2009. Preterm neonates aged $>72$ hours and less than one week were screened for Candida colonization of the groin, oral pharynx and rectum using CHROMagar. Colonized neonates were followed up for 14 days. Blood cultures were done for those with signs of septicaemia.

The Fisher's exact tests and logistic regression were conducted for factors associated with colonization and mortality among colonized neonates. $\mathrm{P}$ values of $<0.05$ were considered significant and confidence interval of $95 \%$ was used.
\end{abstract}

Results: Candida colonization occurred in 50/213 (23.5\%) neonates. Gestational age $\leq 30$ weeks was the only factor independently associated with colonization $(p=0.005)$. Of the colonized 14/46 (30.4\%) died and 13/46 $(28.3 \%)$ developed mucocutaneous candidiasis. No candidemia was identified. Multiple site colonization was independently associated with mortality $(\mathrm{p}=0.035)$.

Conclusion: The consequence of high colonization observed in this study needs to be further elucidated in Uganda.

Key words: Preterm neonates, Candida colonization, Candidemia

DOI: http://dx.doi.org/10.4314/ahs.v15i1.26

\section{Introduction}

The majority of global neonatal deaths take place in low income countries ${ }^{2}$ with the leading causes being prematurity $(28 \%)$ and infections $(26 \%)^{2,3}$. In Uganda infections and preterm births account for $31 \%$ and $25 \%$ of all neonatal deaths respectively ${ }^{4,5}$. Although Candida species exist as commensals on the skin, oropharynx and gastrointestinal tract, invasive candidiasis ${ }^{7-9}$ may oc-

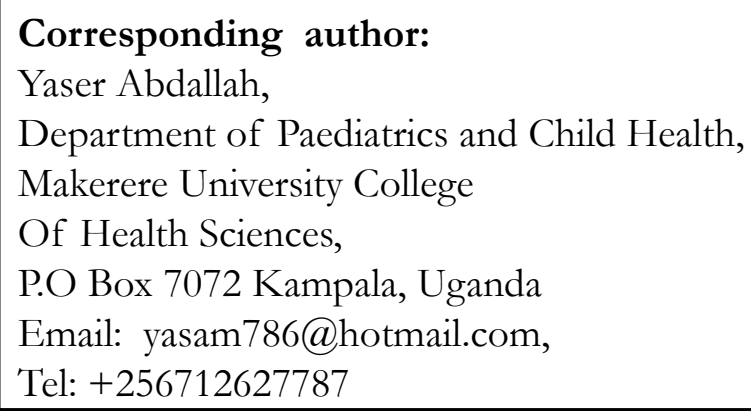

cur among preterm neonates due to immaturity of their immune system ${ }^{6,7}$.

Surveys from some parts of the world have revealed an increase in occurrence of invasive candidiasis in neonatal intensive care units (NICUs) especially among preterm neonates ${ }^{8-10}$ with outbreaks reported from some NICUs ${ }^{11}$. Studies have found that $7-20 \%$ of all Candida colonized preterm neonates develop invasive candidiasis $^{12-15}$ and the most important predictor for invasive candidiasis in neonates is colonization by Candida ${ }^{10,13,16}$. Invasive candidiasis is associated with substantial morbidity as well as a high attributable mortality rate (range, $30-75 \%)^{16}$.

Early diagnosis of invasive candidiasis is challenging hence the shifting of the focus to prevention. Two different Cochrane reviews analyzing antifungal 
prophylaxis using oral/topical nystatin/miconazole D-Absolute errors between the estimated and true valang very low birth ue $=0.05(5 \%)$. P-The prevalence of Candida coloniza weight neonates have demons sive fungal disease among infants receiving anti-fungal prophylaxis ${ }^{17,18}$ tion of $(15.5 \%)$ after 72 hours of life. $\mathrm{n}=\mathrm{Z} 2 \mathrm{P}(1-\mathrm{P})$ $\mathrm{D} 2 \mathrm{n}=1.962 \times 0.155(1-0.155) \quad / 0.052 \quad \mathrm{n}$ (Sample size required) $=201$

Assuming $6 \%$ loss to follow up: Final sample size $=213$ Procedures: Elioible neonates were those $<37$ weeks of In this paper, we describe Candida colonization and gestational age who were $>72$ hours and $<7$ days
candidemia in preterm neonates. Since there was no old. Gestational ages were determined using New candidemia in preterm neonates. Since there was no old. Gestational ages were determined using New
data on the prevalence and outcome of Candida Ballard Score (NBS) performed within 24 hours of colonization of preterm neonates in our settings, admission.

our study findings will provide guidance for care Mothers of eligible neonates were identified; detailed of preterm neonates in Uganda and other low resource settings.

\section{Methods}

Study Site: This study was conducted at the Special Care Unit (SCU) in Mulago hospital. Mulago hospital is a national is a ning tospital where newborn babies who require specialized care are admitted. The unit admits over 2000 low birth weight babies per year with a 35\% mortality among low birth weight babies. The unit has preterm, full term and Kangaroo Mother Care sections.

Most invasive procedures are not carried out in the unit and the available maximum respiratory support is Continuous Positive Airway Pressure (CPAP). The unit is over crowded with most incubators shared by 2 to 3 preterm neonates.

Preterm neonates are discharged from SCU once

they are tolerating oral feeds, gaining weight and maintaining sta care irrespective of their weight or gestational age. A Kangaroo clinic runs in the unit twice a week. Dis-
charged neonates are followed up from this clinic till they attain a weight of $2500 \mathrm{~g}$.

\section{Study design and sample size:}

This was a prospective observational cohort study.

Sample size for prevalence using Kish Leslie method was used since prevalence of Candida colonization was the primary objective. Because no such study had been conducted in Uganda; results from a study in India that found $15.5 \%$ preterm neonates colonized by day 3 of life ${ }^{15}$ was used in estimating sample size and assuming: Z-Standard normal value corresponding to $95 \%$ confi- isolation.

dence interval (1.96)

The study staff used sterile swabs to collect specimen from the groin, oral pharynx and rectum by gently rubbing without prior use of antiseptic. Differen swabs were used for each site. The swabs were placed Amies transport medium, labeled with participants study number and site of collection and transported to the laboratory immediately. Specimens were inoculated on CHROMagar (Becton Dickinson, Sparks MD) and incubated at $37^{\circ} \mathrm{C}$. Agar plates were examined at the microbiology laboratory (Department of Microbiolog Makerere University) for growth at 24, 48 and 72 hours. Candida albicans was identified using CHROMaga cose, Sucrose, Lactose, Maltose and Urase) was used.

Colonized neonates were followed-up for two weeks at the SCU and for those discharged earlier as outpatients. Parents to neonates discharged before laboratory results were back were traced in the follow-up clinic on their scheduled visit.

During the follow-up neonates were examined for ora or perianal thrush and for signs suggestive of septicaemia by World Health Organization criteria ${ }^{1}$. Neonates with oral thrush received nystatin suspension and clotrimazole cream for those with diaper rash.

Blood was collected under aseptic technique from neonates with signs of septicaemia, placed in blood culture bottles with Brain heart infusion agar and transported to laboratory for Candida and bacterial The SCU

Data management and analysis: Data from case report forms was entered into EPI DATA package 3.1 then exported into STATA version 10 for analysis. Univariate analysis was conducted for continuous variables (gestation ages, birth weight and mothers' ages) and results summarized as mean, median and standard deviations.

Continuous variables were categorized and then anaCyzed using Fishe's exact test to determin tion with Candida colonization. Factors with $\mathrm{p}$ value $\leq$ 0.2 in the bivariate analysis were included in the logistic regression model to determine factors independently associated with colonization. $\mathrm{P}$ values of $<0.05$ were considered significant and confidence interval of $95 \%$ was used.

Ethical approval: Approval to carry out this study was granted by the Research and Ethics Committee of Makerere University Medical School. while for non albicans fermentation of sugars (Glu-

\begin{tabular}{|c|c|c|}
\hline Variables & $\begin{array}{c}\text { Frequency } \\
(213)\end{array}$ & $\begin{array}{c}\text { Percentage } \\
(\%)\end{array}$ \\
\hline \multicolumn{3}{|l|}{$\overline{\text { Sex }}$} \\
\hline Male & 101 & 47.7 \\
\hline Female & 112 & 52.3 \\
\hline \multicolumn{3}{|l|}{ Place of birth } \\
\hline Mulago & 138 & 64.8 \\
\hline Other health facility & 52 & 24.4 \\
\hline Home & 23 & 10.8 \\
\hline \multicolumn{3}{|l|}{ Mode of delivery } \\
\hline Vaginal & 174 & 82.0 \\
\hline Caeserian section & 39 & 18.0 \\
\hline \multicolumn{3}{|l|}{ HIV exposure } \\
\hline Not exposed & 175 & 82.2 \\
\hline Exposed & 38 & 17.8 \\
\hline \multicolumn{3}{|l|}{ Gestation Age } \\
\hline $31-36$ weeks & 150 & 70.4 \\
\hline$\leq 30$ weeks & 63 & 29.6 \\
\hline \multicolumn{3}{|l|}{ Birth weights } \\
\hline$\leq 1500$ grams & 126 & 59.2 \\
\hline \multirow{2}{*}{\multicolumn{3}{|c|}{ Axillary temperature $\left({ }^{\circ} \mathrm{C}\right)$}} \\
\hline & & \\
\hline$<36.5$ & 207 & 97.0 \\
\hline$\geq 36.5$ & 6 & 3.0 \\
\hline \multicolumn{3}{|c|}{ Respiratory rate (breaths/min) } \\
\hline$<60$ & 167 & 78.4 \\
\hline & 46 & 21.6 \\
\hline \multicolumn{3}{|l|}{ Pulse rate (beats/min) } \\
\hline$\geq 120$ & 194 & 91.1 \\
\hline$<120$ & 19 & 8.9 \\
\hline
\end{tabular}

Over a five months period (December 2008 to April 2009), 213 preterm neonates were enrolled in the study. Four study participants were discharged early and lost to follow up. Table 1 shows baseline characteristics of study participants. The mean gestational age and birth weight of the study participants were 31.6 weeks (SD 2.3) and $1469 \mathrm{gms}$ (SD 303) respectively. Forty $(18.8 \%)$ of the study participants were small for gestational age. All participants received intraveeceived intravenous aminophylline. Breast milk feed were initiated in $93 \%$ of the study participants prior to enrollment. Two (2) participants received ibuproferterter parenteral lipids. No participant underwent central venous catheterization or intubation and none had commenced kangaroo care prior to enrollment. 
Baseline characteristics were taken at admission 作 was 24 years (SD 5.5). Thirty six mothers $(18.8 \%)$ were tion. Fifty $(23.5 \%)$ of the 213 enrolled preterm neoHIV positive, eight were on HAART and $19(53 \%)$ were nates were colonized. The rectum was the most on cotrimoxazole prophylaxis only. No mother had colonized site. Eighteen (36\%) neonates had received antenatal steroids or antifungal treatment in colonization of more than one site and two had all the the last month of pregnancy. Seventy eight percent of three sites colonized. Four of the colonized neonates mothers reported using herbs all of which were taken had more than one species of Candida.

\begin{tabular}{lcccc}
\multicolumn{6}{l}{ Table 2.Candida species and sites of colonization } \\
\hline Organisms & $\mathbf{n = 7 0 ~ ( \% )}$ & Oral $\mathbf{n}=\mathbf{6}$ & Groin $\mathbf{n}=\mathbf{2 9}$ & Rectal $\mathbf{n}=\mathbf{3 5}$ \\
\hline Candida albicans & $28(40 \%)$ & 2 & 12 & 14 \\
Candida krusei & $21(30 \%)$ & 0 & 10 & 11 \\
Candida glabrata & $13(18.6)$ & 2 & 6 & 5 \\
Candida tropicalis & $2(2.9 \%)$ & 0 & 1 & 1 \\
Unidentified & $6(8.5 \%)$ & 2 & 0 & 4 \\
\hline
\end{tabular}

Four of the colonized preterm
had glabrata + albicans and 1 had glabrata + tropic

Table 3 shows association between baseline charac- life. Nine (20\%) of the colonized neonates developed teristics, interventions and early Candida colonization. clinical sepsis, seven had confirmed bacterial septicaeNo association was found between interventions re- mia; Klebsiella pneumonia (5), Eschericia coli (1) ceived prior to enrollment and colonization. From and Serratia marcescens (1) while two had no isolated multiple regression analysis gestational age $\leq 30$ organisms. Candidemia was not found among these weeks was significantly associated with colonization neonates. Both neonates who had clinical septicae$(\mathrm{p}=0.005)$. During follow-up, $13 / 46(28 \%)$ of the col- mia with negative blood cultures had more than one onized neonates developed mucocutaneous candidiasis site colonized and one neonate developed mucocutane(oral + /- diaper) occurring between day 6 and 12 of ous candidiasis.
Table 3 Association between baseline characteristics, interventions and early Candida $\frac{\text { colonization }}{\text { Variables }}$

\begin{tabular}{|c|c|c|c|c|}
\hline \multirow[t]{2}{*}{ Variables } & \multicolumn{2}{|c|}{ Candida colonization } & \multirow{2}{*}{$\begin{array}{l}\text { OR } \\
(95 \% \mathrm{CI})\end{array}$} & \multirow[t]{2}{*}{ p-value } \\
\hline & No $(\mathrm{N}=163)$ & Yes $(\mathrm{N}=50)$ & & \\
\hline \multicolumn{5}{|l|}{ Sex } \\
\hline Male & $78(47.8 \%)$ & $23(46 \%)$ & \multirow{2}{*}{$\begin{array}{l}0.93 \\
(0.46-1.84)\end{array}$} & \multirow{2}{*}{0.818} \\
\hline Female & $85(52.2 \%)$ & $27(54 \%)$ & & \\
\hline \multicolumn{5}{|l|}{ Place of birth } \\
\hline Mulago & $108(66.3 \%)$ & $30(60 \%)$ & \multirow{3}{*}{$\begin{array}{l}1.00 \\
(0.30-3.30)\end{array}$} & \multirow[t]{3}{*}{0.444} \\
\hline Other health facility & $36(22 \%)$ & $16(32 \%)$ & & \\
\hline Home & $19(11.7 \%)$ & $4(8 \%)$ & & \\
\hline \multicolumn{5}{|l|}{ Mode of delivery } \\
\hline Vaginal & $131(80.4 \%)$ & $43(86 \%)$ & 1.50 & \multirow[t]{2}{*}{0.411} \\
\hline Caesarian section & $32(82.0 \%)$ & $7(14 \%)$ & $(0.50-4.30)$ & \\
\hline \multicolumn{5}{|l|}{ HIV exposure } \\
\hline Not exposed & $130(80.0 \%)$ & $45(90 \%)$ & 0.43 & \multirow[t]{2}{*}{0.138} \\
\hline Exposed & $33(20.0 \%)$ & $5(10 \%)$ & $(0.13-1.23)$ & \\
\hline \multicolumn{5}{|l|}{ Gestational age } \\
\hline $31-36$ weeks & $123(81.0 \%)$ & $27(54 \%)$ & 2.60 & \multirow[t]{2}{*}{0.004} \\
\hline$\leq 30$ weeks & $40(19.0 \%)$ & $23(46 \%)$ & $(1.20-5.30)$ & \\
\hline \multicolumn{5}{|l|}{ Birth weight } \\
\hline$\leq 1500$ grams & $90(55.2 \%)$ & $36(72 \%)$ & 2.08 & \multirow[t]{2}{*}{0.047} \\
\hline$>1500$ grams & $73(44.8 \%)$ & $14(28 \%)$ & $(1.00-4.50)$ & \\
\hline \multicolumn{5}{|l|}{ Duration of rupture of } \\
\hline Membranes & & & & \multirow{3}{*}{0.920} \\
\hline$<24$ hours & $125(77.0 \%)$ & $38(76 \%)$ & 1.03 & \\
\hline$\geq 24$ hours & $38(23.0 \%)$ & $12(24 \%)$ & $(0.44-2.28)$ & \\
\hline \multicolumn{5}{|l|}{ Oral Suction* } \\
\hline No & $148(91.0 \%)$ & $48(96 \%)$ & 0.41 & \multirow[t]{2}{*}{0.371} \\
\hline Yes & $15(9.0 \%)$ & $2(4 \%)$ & $(0.04-1.87)$ & \\
\hline \multicolumn{5}{|l|}{ CPAP } \\
\hline No & $151(92.7 \%)$ & $46(92 \%)$ & 1.09 & \multirow[t]{2}{*}{1.000} \\
\hline Yes & $12(7.3 \%)$ & $4(8 \%)$ & $(0.24-3.84)$ & \\
\hline \multicolumn{5}{|l|}{ Initiation of breast milk } \\
\hline Yes & $155(95.1 \%)$ & $45(90 \%)$ & 2.15 & \multirow{2}{*}{0.190} \\
\hline No & $8(4.9 \%)$ & $5(10 \%)$ & $(0.52-7.86)$ & \\
\hline Small for gestational age & & & & \\
\hline Yes & $32(19.6 \%)$ & $8(16.0 \%)$ & 0.82 & 0.773 \\
\hline No & $131(80.4 \%)$ & $42(84.0 \%)$ & $(0.42-1.64)$ & \\
\hline Variable & $\begin{array}{c}\text { COR }^{*} \\
(95 \% \text { CI) }\end{array}$ & p-value & $\begin{array}{c}\mathrm{AOR}^{*} \\
(95 \% \mathrm{CI})\end{array}$ & p-value \\
\hline $\begin{array}{r}\text { Gestational age } \\
\leq 30 \text { weeks }\end{array}$ & $\begin{array}{c}2.619 \\
(1.27-5.33)\end{array}$ & 0.004 & $\begin{array}{c}2.60 \\
(1.33-5.10)\end{array}$ & 0.005 \\
\hline HIV exposure & $\begin{array}{c}0.437 \\
(0.13-1.23)\end{array}$ & 0.138 & $\begin{array}{c}0.45 \\
(0.16-1.22)\end{array}$ & 0.116 \\
\hline Not Initiated on & 2.153 & 0.190 & 1.04 & 0.994 \\
\hline Breast milk & $(0.52-7.86)$ & & $(0.3-3.5)$ & \\
\hline
\end{tabular}

* Preterm neonates delivered from other health facilities; if suction was not mentioned then it was assumed not done.
COR* Crude Odds ratio, AOR*Adjusted Odds Ratio 
Out of 46 colonized neonates $14(30 \%)$ died. Eight and parents declined postmortem. Table 4 shows facdied from septicaemia, four from suspected necrotiz- tors associated with mortality among Candida coloing enterocolitis (NEC), and two from aspiration of nized neonates. There was no association between feeds. All neonates who died from suspected NEC had Candida species responsible for colonization with ocCandida rectal colonization, three had more than one currence of mucocutaneous candidiasis, bacterial sepsite colonized, and two of them had mucocutaneous ticaemia or death. On logistic regression association candidiasis. All neonates who died from suspected between multiple sites of Candida colonization and NEC, deteriorated following rapid progression of mortality remained statistically significant $\mathrm{p}=0.035 \mathrm{al}-$ suspected NEC, no blood for cultures were obtained though the numbers were small.

Table 4. Bivariate and multivariate analysis of Factors associated with mortality among

Candida colonized preterm neonates.

\begin{tabular}{|c|c|c|c|c|}
\hline \multirow[t]{2}{*}{ Variable } & \multicolumn{2}{|c|}{$\mathrm{N}=46(\%)$} & \multirow{2}{*}{$\begin{array}{l}\text { COR * } \\
(95 \% \mathrm{CI})\end{array}$} & \multirow[t]{2}{*}{ p-value } \\
\hline & $\begin{array}{c}\text { Died } \\
(\mathrm{N}=14)\end{array}$ & $\begin{array}{c}\text { Alive } \\
(\mathbf{N}=\mathbf{3 2})\end{array}$ & & \\
\hline \multicolumn{5}{|l|}{ Sites colonized $\dagger$} \\
\hline$>1$ site & $9(64.3 \%)$ & $7(22 \%)$ & 6.4 & 0.0084 \\
\hline 1 site & $5(35.7 \%)$ & $25(78 \%)$ & $(1.34-32.15)$ & \\
\hline \multicolumn{5}{|l|}{ Mucocutaneous } \\
\hline \multicolumn{5}{|l|}{ Candidiasis } \\
\hline Yes & $2(14.3 \%)$ & $11(34.4 \%)$ & 0.32 & 0.286 \\
\hline No & $12(85.7 \%)$ & $21(65.6 \%)$ & $(0.03-1.89)$ & \\
\hline \multicolumn{5}{|l|}{ Bacterial septicaemia } \\
\hline Yes & $6(43 \%)$ & $1(3.1 \%)$ & 23.0 & 0.0019 \\
\hline No & $8(57 \%)$ & $31(96.9 \%)$ & $(2.14-1102)$ & \\
\hline \multicolumn{5}{|l|}{ Gestation age } \\
\hline$\leq 30$ weeks & $12(85.7 \%)$ & $10(31.3 \%)$ & 13.2 & 0.001 \\
\hline \multirow{2}{*}{\multicolumn{5}{|c|}{ C. Albican colonization* }} \\
\hline & & & & \\
\hline Yes & $8(61.5 \%)$ & $13(46.6 \%)$ & 1.84 & 0.505 \\
\hline No & $5(38.5 \%)$ & $15(53.6 \%)$ & $(0.40-8.99)$ & \\
\hline \multicolumn{5}{|l|}{ C. Krusei colonization* } \\
\hline Yes & $4(31 \%)$ & $13(46.4 \%)$ & 0.51 & 0.498 \\
\hline No & $9(69 \%)$ & $15(53.6 \%)$ & $(0.094-2.44)$ & \\
\hline \multicolumn{5}{|c|}{ C. Non-albican \& non- krusei* } \\
\hline Yes & $2(15.4 \%)$ & $3(10.7 \%)$ & 1.51 & 0.645 \\
\hline No & $11(84.6 \%)$ & $25(89.3 \%)$ & $(0.11-15.1)$ & \\
\hline Variable & $\begin{array}{c}\begin{array}{c}\text { COR* } \\
(95 \% C I)\end{array} \\
\end{array}$ & p-value & $\begin{array}{c}\text { AOR * } \\
(95 \% \text { CI) }\end{array}$ & p-value \\
\hline$>1$ site colonized & $\begin{array}{l}6.242 \\
(1.34-32.1)\end{array}$ & 0.0084 & $\begin{array}{c}6.41 \\
(1.143-36.0)\end{array}$ & 0.035 \\
\hline Gestation age $\leq 30$ weeks & $\begin{array}{c}13.2 \\
(2.17-134.5)\end{array}$ & 0.001 & $\begin{array}{c}7.07 \\
(1.057-47.3)\end{array}$ & 0.044 \\
\hline Bacterial septicaemia & 23 & 0.0019 & 9.4 & 0.08 \\
\hline
\end{tabular}

4 preterm neonates were lost to follow up. $\uparrow 2$ preterm neonates who were lost to follow up had $>1$ site colonized. $* 5$ of the colonized preterm neonates had species that were not identified; they were excluded from analysis for association between Candida species colonized with and outcome
The prevalence of Candida colonization observed of $23.5 \%$ is comparable to $26.2 \%$ that was observed by Mandiratta et al in India during the first week of life $\mathrm{e}^{15}$ but higher than those observed in other centers ${ }^{19-21}$. Our prevalence might actually be an under estimation since we did not screen for colonization prior to 72 hours of life yet studies we are comparing with screened study subjects from the first 24 hours of life. Al though other studies did not describe the day to day activities of their units, SCU is small, overcrowded with sharing of incubators and mothers are involved in the nursing care. These factors can potentiate person to person transmission of Candida since horizontal transmission has been shown to be an equally important route of Candida acquisition 22,2

Gestational age $\leq 30$ weeks was the only factor independently associated with Candida colonization $(p=0.005)$. This finding is similar to the findings from other studies ${ }^{15,20,21}$. The association of Candida colonization and lower gestational age is partly due to prematurity being associated with compromised immunity ${ }^{6,7}$. The other explanation for this association may lie in the excessive handling that preterm neonates inevitably undergo while in neonatal units that promotes horizontal acquisition ${ }^{23}$. There was no association observed between small for gestational age study participants and Candida colonization $(\mathrm{p}=0.82)$, no other studies that we came across looked at small for gestational age and colonization. Our study finding is contrary to knowledge that these neonates are susceptible to infections due to some degree of immunosuppression ${ }^{24}$. One possible explanation for lack of association may be that the small for gestational age neonates tend to be stable hence have less frequent handling and therefore lower risk of horizontal acquisition of Candida.

In our study the odds of being colonized with Candida whe a neonte was di not statistically significant $(p=0.411)$. Findings from other studies demonstrated vaginal delivery as being associated with Candida colonization ${ }^{15,21,23}$. The lack of statistical significance found in our study may be attributed to Prolonged Rupture of Membranes (PROM) $\geq 24$ hours which occurred in $41 \%$ of the mothers who delivered by caesarian section and because we did not screen for colonization within first 24 hours, some of ge might have been colonized.

After controlling for PROM, the association of colonization and vaginal delivery was not statistically significant $(\mathrm{p}=0.389)$. This supports the possibility that Candida colonization identified after 72 hours of life is more likely acquired from the environment ${ }^{22,23}$

PROM for $\geq 24$ hours has been associated with ascending infections and neonatal septicaemia. In this study there was no association between PROM and Candida colonization $(p=1.000)$. This finding correlates with findings from other studies ${ }^{20,21}$ but contrary to findings by Mandiratta et al which found a significant association $(p=<0.05)(15)$. Although they didn't specify hours of rupture of membranes, Mandiratta et al screened mothers for Candida vaginal colonization and found $29.8 \%$ of mothers were colonized with some isolated species resembling those responsible for neonatal colonization. Maternal HIV has been associated with higher vaginal Candida colonization especially as the mothers' immunological state deteriorates ${ }^{25}$. The association between HIV exposure and Candida colonization was not statistically significant ( $\mathrm{p}$ $=0.138)$ even after controlling for mode of delivery $(\mathrm{p}=0.124)$. The possible explanation is that most of the HIV infected mothers were receiving HIV care and possibly their immunological status were good hence ess carriage of Candida.

Interventions received prior to enrollment were not associated with Candida colonization. The odds of being colonized if breast milk had not been initiated was $2.15(95 \% \mathrm{CI}, 0.525-7.866)$ although it was not statistically significant $(\mathrm{p}=0.190)$. This finding could be attributed to the presence of lactobacillus in the breast milk that has been demonstrated to reduce gut Candida colonization in preterm neonates ${ }^{26,27}$.

Mucocutaneous Candidiasis occurred in 28\% of colonized neonates between the 6th and 12th day of life. These findings were similar to those observed in other studies one describing mucocutaneous candidiasis in a third of colonized neonate ${ }^{20}$ and another describing the time of occurrence as 2nd to 3rd week of life $^{28}$. Although other studies have reported candidemia in $7-20 \%$ of colonized preterm neonates, in our study, we did not find any. This may be due to the fact that our study did not have extremely premature 
neonates who are more susceptible and the unit does minimal invasive procedures hence minimizing risk for Candidemia. Although studies have shown that multiple body site colonization with Candida is associated with candidemia ${ }^{13,29}$, our study did not find this association. However, mortality was significantly associated with more than one site colonization. The main cause of mortality among our study neonates was bacterial sepsis; the factors predisposing these neonates to bacterial sepsis may be the same factors that predispose them to early Candida colonization ${ }^{30}$.

The study limitations included an underestimated prevalence since we did not screen for colonization within 24 hours of life. Our data was skewed with the majority of our study subjects being $>30$ weeks gestation, since most of the extremely preterm neonates in our unit do not survive beyond 72 hours of life. The study was not powered enough to study associations and our inability to do postmortem on study participants who died especially those with suspected NEC might have compromised identification of invasive candidiasis.

Conclusion: In view of the perceived threat of Candidemia among this population with the high colonization and low levels of candidemia observed in this study, the consequence of early colonization needs to be further elucidated in Uganda

\section{What is already known on this subject}

Candida colonization among preterm neonates is a predictor for invasive candidiasis. Antifungal prophylaxis among preterm neonates effectively reduces fungal colonization and invasive disease.

\section{What this study adds}

Early Candida colonization of preterm neonates in a low-resource setting is very prevalent. Candidemia is not common.

\section{Conflict of interest}

The study funders did not actively participate in the study and none of the authors had any conflict of interest.

\section{Contributorship statement}

Abdallah Yaser was the principal investigator; he did the literature search, data collection, entry and the writing up of this work. Philippa Musoke and Jolly Nankunda were involved in study design and methodology; re- ewed the write up, data analysis and interpretation of en laboratory techniques appropriate and reviewed results.

\section{Acknowledgements}

We would like to thank the staff of the Special Care Unit, the departments of Paediatrics and Medical Microbiology of Makerere University College of Health Sciences for the assistance extended during the study.

\section{References:}

WHO. The sick young infant ages 1 week to 2 months Assess and classify. In: WHO, editor. Handbook: IMC integrated management of childhood illnesses Geneva: WHO; 2005. p. 59-72.

2. Lawn JE, Cousens S, Zupan J, Lancet Neonatal Survival Steering Team. 4 million neonaal deaths: when? Where? Why? Lancet 2005 Mar 5-11;365(9462):891-900

3. WHO- Neonatal and Perinatal Mortality. Country, Regional and Global estimates. 2006.

4. Jessica Jitta DK. Situation Analysis of Newborn Health in Uganda. 2008.

5. UNICEF. UNICEF: Uganda Country profile: Maternal, Newborn and Child Survival. 112010

6. Kaufman D, Kilpatrick L, Hudson RG, Campbel DE, Kaufman A, Douglas SD, et al. Decreased superoxide production, degranulation, tumor necrosis factor alpha secretion, and CD11b/CD18 receptor expression by adherent monocytes from preterm infants. Clin $\mathrm{Di}-$ agn Lab Immunol 1999 Jul;6(4):525-529.

. Marodi, L., and R. B. Johnston, Jr. editor. Fetal and Neonatal Physiology. R.A. Polin, W. W. Fox, and S. H. Abman (ed) ed.: The W.B. Saunders Co., Philadelphia, Pa.; 2004

8. Makhoul IR, Sujov P, Smolkin T, Lusky A, Reichman B. Epidemiological, clinical, and microbiological characteristics of late-onset sepsis among very low birth weight infants in Israel: a national survey. Pediatrics 2002 Jan;109(1):34-39.

9. Stoll BJ, Hansen N, Fanaroff AA, Wright LL, Carlo WA, Ehrenkranz RA, et al. Late- onset sepsis in very low birth weight neonates: the experience of the NICHD Neonatal Research Network. Pediatrics 2002 Aug;110(2 Pt 1):285-291.

10. Saiman L, Ludington E, Pfaller M, Rangel-Frausto S, Wiblin RT, Dawson J, et al. Risk factors for candidemia in Neonatal Intensive Care Unit patients. The National Epidemiology of Mycosis Survey study group. Pediatr Infect Dis J 2000 Apr;19(4):319-324.

11. Huang YC, Lin TY, Leu HS, Peng HL, Wu
$\mathrm{JH}$, Chang HY. Outbreak of Candida parapsilosis fungemia in neonatal intensive care units: clinical implications and genotyping analysis. Infection $1999 \mathrm{Mar}-$ Apr;27(2):97-102.

12. Huang YC, Li CC, Lin TY, Lien RI, Chou YH, Wu $\mathrm{JL}$, et al. Association of fungal colonization and invasive disease in very low birth weight infants. Pediatr Infect Dis J 1998 Sep;17(9):819-822.

13. Manzoni P, Farina D, Leonessa M, d'Oulx EA, Galletto P, Mostert M, et al. Risk factors for progression to invasive fungal infection in preterm neonates with fungal colonization. Pediatrics 2006 Dec;118(6):2359-2364. 14. Singh K, Chakrabarti A, Narag A, et al. Yeast colonization and fungemia in preterm neonates in tertiary care centre. Indian Journal of Medical Research 1999;110:169-73

15. Mendiratta DK, Rawat V, Thamke D, et al. Candida colonization in preterm babies admitted to neonatal intensive care unit in the rural setting. Indian J Med Microbiol 2006 Oct;24(4):263-267.

16. Benjamin DK Jr, Stoll BJ, Fanaroff AA, McDonald SA, Oh W, Higgins RD, et al. National Institute of Child Health and Human Development Neonatal Research Network. Neonatal candidiasis among extremely low birth weight infants: risk factors, mortality rates, and neurodevelopmental outcomes at 18 to 22 months. Pediatrics 2006 Jan;117(1):84-92.

17. Austin N, Darlow BA, McGuire W. Prophylactic oral/topical non-absorbed antifungal agents to prevent invasive fungal infection in very low birth weight infants. Cochrane Database Syst Rev 2009 Oct 7;(4):CD003478. doi(4):CD003478

18. Clerihew L, Austin N, McGuire W. Prophylactic systemic antifungal agents to prevent mortality and morbidity in very low birth weight infants. Cochrane Database Syst Rev 2007 Oct 17;(4)(4):CD003850.

19. Ali GY, Algohary EH, Rashed KA, Almoghanum M, Khalifa AA. Prevalence of Candida colonization in preterm newborns and VLBW in neonatal intensive care unit: role of maternal colonization as a risk factor in transmission of disease. J Matern Fetal Neonatal Med 2012 Jun;25(6):789-795.

20. Baley JE, Kliegman RM, Boxerbaum B, Fanaroff AA. Fungal colonization in the very low birth weight infant. Pediatrics 1986 Aug:78(2):225-232

21. Farmaki E, Evdoridou J, Pouliou T, Bibashi E, Pa- gopoulou P, Filioti J, et al. Fungal colonization in the neonatal intensive care unit: risk factors, drug susceptibility, and association with invasive fungal infections. Am J Perinatol 2007 Feb;24(2):127-135.

22. Bliss JM, Basavegowda KP, Watson WJ, Sheikh AU, Ryan RM. Vertical and horizontal transmission of

Candida albicans in very low birth weight infants using DNA fingerprinting techniques. Pediatr Infect Dis J 2008 Mar;27(3):231-235.

23. Saiman L, Ludington E, Dawson JD, National Epidemiology of Mycoses Study Group. Risk factors for Candida species colonization of neonatal intensive care unit patients. Pediatr Infect Dis J 2001 Dec;20(12):1119 1124

24. Xanthou M. Immunologic deficiencies in smallfor-dates neonates. Acta Paediatr Scand Suppl 1985(319):143-9.

5. Ohmit SE, Sobel JD, Schuman P, et al, HIV Epidemiology Research Study (HERS) Group. Longitudinal study of mucosal Candida species colonization and candidiasis among human immunodeficiency virus (HIV) seropositive and at-risk HIV-seronegative women. $J$ Infect Dis 2003 Jul 1;188(1):118-127.

66. Manzoni P, Mostert M, Leonessa ML, et al. Ora supplementation with Lactobacillus casei subspecies hamnosus prevents enteric colonization by Candid species in preterm neonates: a randomized study. Clin Infect Dis 2006 Jun 15;42(12):1735-1742.

27. Manzoni P. Use of Lactobacillus casei subspecies Rhamnosus GG and gastrointestinal colonization by Candida species in preterm neonates. J Pediatr Gastroenterol Nutr 2007 Dec;45 Suppl 3:S190-4.

28. Faix RG, Kovarik SM, Shaw TR, Johnson RV. Mucocutaneous and invasive candidiasis among very low birth weight (less than 1,500 grams) infants in intensive care nurseries: a prospective study. Pediatrics 1989 an;83(1):101-107.

29. Manzoni P, Farina D, Galletto P, Leonessa M Priolo C, Arisio R, et al. Type and number of sites colonized by fungi and risk of progression to invasive fungal infection in preterm neonates in neonatal intensive care unit. J Perinat Med 2007;35(3):220-226. 30. Manzoni P, Farina D, Monetti C,et al. Earlyonset neutropenia is a risk factor for Candida colonization in very low-birth-weight neonates. . Diagn Microbiol Infect Dis 2007 Jan;57(1):77-83. 